\title{
DIREITOS SOCIAIS E PESSOAS EM SITUAÇÃO DE RUA: ANÁLISE DA (IN) VISIBILIDADE DE PESSOAS EM SITUAÇÃO DE RUA
}

Tatiane Campelo da Silva Palhares*

\section{RESUMO}

Este ensaio objetiva refletir sobre a condição de pessoas em situação de rua a partir do mínimo existencial para o alcance dos direitos sociais. Destaca-se na pesquisa o método qualitativo, ao qual parte de aspectos subjetivos para demonstrar a ênfase em elementos normativos da justiça. O problema: as pessoas em situação de rua são excluídas do mínimo existencial em face dos direitos sociais, logo não possuem as condições mínimas para existência humana? Resultado: que não é possível a construção de uma sociedade com desenvolvimento nacional, se inexistente a identificação das pessoas em situação de rua, para promoção dos direitos sociais.

Palavras-Chave: Pessoas em Situação de Rua; Mínimo Existencial; Direitos Sociais; Exclusão Social; Invisibilidade.

\section{SOCIAL RIGHTS AND PEOPLE IN STREET SITUATION: ANALYSIS OF THE (IN) VISIBILITY OF PEOPLE IN STREET SITUATION}

\begin{abstract}
This essay aims to reflect on the condition of people on the street from the minimum existential to achieve social rights. The qualitative method stands out in the research, which starts from subjective aspects to demonstrate the emphasis on normative elements of justice. The problem: people on the street are excluded from the existential minimum in the face of social rights, so they do not have the minimum conditions for human existence? Result: that it is not possible to build a society with national development, if there is no identification of people on the street, to promote social rights.
\end{abstract}

Keywords: Street People; Existential Minimum; Social rights; Social exclusion; Invisibility.

\section{INTRODUÇÃO}

Discorrer sobre o tema referente às pessoas em situação de rua e os direitos sociais consiste na reflexão de que é preciso ampliá-los, protegê-los e promovê-los, sempre, na ordem interna, atuando de forma proativa na formulação de políticas públicas que enfrentem o

\footnotetext{
* Pós-doutorado em Direito Constitucional. Doutora em Direito Constitucional pela Universidade de Fortaleza (UNIFOR). Professora de Direito Administrativo e servidora pública da Secretaria de segurança do Estado do Amazonas. E-mail: tatianeplhares@hotmail.com
} 
problema da exclusão social, permitindo que todas às pessoas tenham real acesso ao mínimo existencial.

$\mathrm{O}$ artigo objetiva refletir sobre o prisma do direito constitucional em face da condição de pessoas em situação de rua para a efetivação do mínimo existencial. A pesquisa destaca o método qualitativo, ao qual parte de aspectos subjetivos para demonstrar a ênfase em elementos normativos da justiça e sistematizar parâmetros para a reflexão de garantias dos direitos humanos das pessoas em situação de rua. No tocante ao problema da pesquisa que corresponde a seguinte indagação: as pessoas em situação de rua são excluídas do mínimo existencial em face dos direitos sociais, logo não possuem as condições mínimas para existência humana?

De toda sorte, o que se verifica é que a insuficiência ou total ausência de direitos sociais para às pessoas em situação de rua, decorre do fato da administração pública que usa de forma fragmentada e injustificada os princípios e normas nas tomadas de decisões para a efetivação de políticas públicas. O presente preâmbulo, encerra-se com a seguinte estrutura e desenvolvimento do artigo:

a) Pessoas em Situação de Rua: análise do plano nacional (Decreto $n^{\circ}$ 7053/2009). Aborda os direitos da pessoa humana em face das nuances do plano nacional para às pessoas em situação de rua.

b) Direitos Humanos: olhares sobre a pessoa humana. Reflete sobre a historicidade dos direitos humanos;

c) política nacional para às pessoas em situação de rua: contextualizando. Analisa a Política Nacional para às pessoas em situação de rua e suas facetas históricas;

d) a Constituição brasileira e os direitos fundamentais: análise sob a ordem nacional e internacional. Reflete sobre os direitos fundamentais na Constituição brasileira de 1988.

Na busca do desenvolvimento deste ensaio, revela-se a importância do entendimento da condição das pessoas em situação de rua, bem como a relação com o termo mendicância. Isso em termos de configuração histórica relaciona-se a um fato determinado que foi o surgimento da propriedade privada, que manteve e mantém constantemente uma camada de excluídos e rejeitados pelo modo de produção, em todas as formações sociais, bem como os inaptos 
físicos ou psíquicos, as vítimas de guerra e da própria estrutura econômica, os camponeses expulsos ou trabalhadores urbanos desempregados.

\section{Pessoas em situação de rua: análise do plano nacional (Decreto $\mathbf{n}^{0}$. 7.053/2009)}

A partir da deferência conferida ao contexto internacional para esclarecer as nuances dos Direitos Humanos, faz-se necessário destacar que no contexto nacional, o Decreto $\mathrm{n}^{\circ}$. 7.053/2009, que “instituiu a Política Nacional para População em Situação de Rua e seu Comitê Intersetorial de Acompanhamento e Monitoramento (...)” (BRASIL, 2012a), destacando, ainda, a implementação de forma descentralizada e articulada entre a União e os demais entes federativos para acolhimento das pessoas em situação de rua.

O Decreto $n^{\circ}$. 7.053/2009, em seu parágrafo único do art. $1^{\circ}$, define a população em situação de rua como:

[...] grupo populacional heterogêneo que possui em comum a pobreza extrema, os vínculos familiares interrompidos ou fragilizados e a inexistência de moradia convencional regular, e que utiliza os logradouros públicos e as áreas degradadas como espaço de moradia e de sustento, de forma temporária ou permanente, bem como as unidades de acolhimento para pernoite temporário ou com moradia provisória.

Outra definição para às pessoas em situação de rua foi empreendida pelo Ministério do Desenvolvimento Social e Combate à Fome - MDS na pesquisa censitária amostral de 2007:

\footnotetext{
Grupo populacional heterogêneo, caracterizado por sua condição de pobreza extrema, pela interrupção ou fragilidade dos vínculos familiares e pela falta de moradia convencional regular. São pessoas compelidas a habitar logradouros públicos (ruas, praças, cemitérios etc), áreas degradadas (galpões e prédios abandonados, ruinas etc) e, ocasionalmente, utilizar abrigos e albergues para pernoitar.
}

A população em situação de rua, portanto, é composta por sujeitos despojados de seus direitos mais básicos. Essas pessoas têm em comum a vida em condições precárias, seja por questões circunstancial, seja por questão permanente. As tentativas de caracterizar esse segmento populacional ainda são incipientes por tratar-se de grupo heterogêneo. Dentre os 
seus membros há imigrantes, desempregados, egressos dos sistemas prisionais e de hospitais psiquiátricos, entre outras pessoas. Saliente-se que uma parcela desses indivíduos não tem endereço fixo e que, embora alguns deles o tenham, a maioria permanece grande parte do tempo em logradouros públicos.

Aferir quantitativamente o contingente populacional que habita às ruas é uma necessidade imediata e desafiadora para órgãos oficiais e não oficiais, uma vez que essa população não integra a base de dados das pesquisas tradicionais do Instituto Brasileiro de Geografia e Estatística (IBGE), cujo fator norteador é a moradia.

O Ministério do Desenvolvimento Social e Combate à Fome arriscou-se a mensurar nos municípios brasileiros o contingente de "pessoas em situação de rua" e a obter dados qualitativos das condições de vida desse segmento.

A pesquisa censitária amostral nacional pressupôs que os municípios mais populosos e as capitais dos Estados tenderiam a uma maior concentração de pessoas em situação de rua, pois tais logradouros propiciam maiores oportunidades de emprego e sobrevivência das pessoas em situação de vulnerabilidade.

Por meio da aplicação de questionários, foram selecionados 71 municípios (sendo 23 capitais) com população igual ou superior a 300.000 habitantes. O resultado da pesquisa foi: 31.922 pessoas (maiores de 18 anos) em situação de rua no Brasil.

Os dados levantados revelam o perfil populacional (características socioeconômicas e formação escolar); a trajetória de rua (razões de ida à rua, deslocamento, entre outros); o histórico de internação em instituições; o pernoite, vínculos familiares e trabalho; o acesso à alimentação, serviços e cidadania; as discriminações sofridas; a participação em movimentos sociais.

As informações obtidas são importantes para nortear a elaboração de políticas públicas e o planejamento de ações sociais implementadas pela sociedade civil. É premente destacar a necessidade de romper com o paradigma dos programas assistencialistas, paternalistas, autoritários e, por vezes, de "higienização social", a fim de adotar ações inclusivas com o propósito de reinserção das pessoas em situação de rua na família, trabalho, moradia e saúde, para que o segmento possa ter o direito à cidadania.

Ademais, com as informações obtidas, foi possível refletir sobre o objetivo da Política Nacional para População em Situação de Rua, que destaca os seguintes objetivos: 
I- Assegurar o acesso amplo, simplificado e seguro aos serviços e programas que integram as políticas públicas de saúde, educação, previdência, assistência social, esporte, moradia, segurança, cultura, lazer, trabalho e renda;

II- Garantir a formação e capacitação permanente de profissionais e gestores para atuação no desenvolvimento de políticas públicas intersetoriais transversais e intergovernamentais direcionadas às pessoas em situação de rua;

III- Instituir a contagem oficial da população em situação de rua; $[\ldots]$

Tais objetivos retratam um cenário que busca amenizar ou evitar que às pessoas em situação de rua possam sofrer violências, e, assim ter o alcance dos seus direitos enquanto cidadão. É fato, que a violência marca e restringe às pessoas em situação de rua para um enfretamento diário das mazelas sociais, seja na ausência da concretização dos seus direitos, seja pela vulnerabilidade que se encontram, ou ainda, pela inversão do espaço público em privado (as ruas que se tornam local de moradia).

\section{Direitos Humanos: olhares sobre a pessoa humana}

Os Direitos Humanos consistem em um conjunto de direitos considerados indispensáveis à concretização da dignidade humana, sendo imprescindíveis para que a vida em sociedade seja pautada na liberdade, igualde e dignidade. É dizer, direitos humanos são aqueles inerentes a todos os seres humanos, independentemente da raça, nacionalidade, etnia, idioma, religião ou qualquer outra condição.

Desta feita, a dignidade humana consiste na qualidade intrínseca e distintiva de cada ser humano, que o protege contra todo tratamento degradante e discriminação odiosa, bem como assegura condições materiais de sobrevivência. Trata-se de atributo que todo individuo possui, inerente à sua condição humana, não importando qualquer outra condição referente à nacionalidade, opção política, orientação sexual, credo entre outros (MORAES, 2010).

A expressão Direitos Humanos, tanto no contexto do Direito Internacional quanto no Direito Nacional, apresenta uma utilização variada e intercambiante de expressões. Assim, a 
Declaração Americana dos Direitos e Deveres do Homem de 1948 utiliza no seu preâmbulo, os termos "direito do homem" e "direitos essenciais do homem".

A Declaração Universal de Direitos Humanos, por seu turno, estabelece em seu preâmbulo a necessidade de respeito aos "direitos do homem" e logo após a "fé nos direitos fundamentais do homem" e ainda o respeito "aos direitos e liberdades fundamentais do homem".

A Carta da Organização das Nações Unidas emprega a expressão "direitos humanos" (preâmbulo e artigo 56), bem como "liberdades fundamentais" (artigo 55, alínea “c”). A Carta dos Direitos Fundamentais da União Europeia do ano de 2000 (revisada em 2007) utiliza o termo "direitos fundamentais" e a Convenção Europeia de Direitos do Homem e Liberdades Fundamentais usa o termo "liberdade fundamental".

Assim, na necessidade de se adotar uma definição concisa entende-se por direitos humanos como sendo um conjunto mínimo de direitos necessários para assegurar uma vida do ser humano baseada na liberdade, igualdade.

A dignidade, é a qualidade intrínseca e distintiva de cada ser humano que o faz merecedor de respeito e consideração por parte do Estado e da comunidade, implicando nesse sentido um complexo de direitos e deveres fundamentais. Os direitos humanos, por sua vez, asseguram uma vida digna, na qual o indivíduo possui condições adequadas de existência, participando ativamente da vida em comunidade.

Para Cançado Trindade (1991), o desenvolvimento histórico da proteção dos direitos humanos gradualmente superou barreiras do passado, pois compreendeu-se, pouco, que a proteção dos direitos básicos da pessoa humana não se esgota, como não poderia esgotar-se.

Com isso, a afirmação da historicidade dos direitos humanos é marcada por constante renovação, desde a antiguidade aos dias de hoje. Por isso, a abordagem tradicional do conteúdo dos direitos humanos é chamada de "geração de direitos".

Tal teoria foi lançada pelo jurista francês VASAK (1997) que em conferência proferida no Instituto Internacional de Direitos Humanos no ano de 1973, classificou os direitos humanos em três gerações, cada uma com características próprias.

A primeira geração engloba os chamados direitos de liberdade, que são direitos às chamadas prestações negativas, nas quais o Estado deve proteger a esfera de autonomia do indivíduo. Por isso, são conhecidos como direitos ou liberdades individuais, que tem como marco as revoluções liberais do século XVIII na Europa e Estados Unidos, que visavam 
restringir o poder absoluto do monarca, impondo limites à ação estatal. São entre outros, o direito à liberdade, igualdade perante a lei, propriedade, intimidade e segurança, traduzindo o valor da liberdade. Saliente-se que o papel do Estado na defesa dos direitos de primeira geração é tanto o tradicional papel passivo (abstenção em violar os direitos humanos, ou seja, as famosas prestações negativas) quanto ativo, pois há de se exigir ações do Estado para garantia da segurança pública, administração da justiça, entre outras.

A segunda geração de direitos humanos representa a modificação do papel do Estado, exigindo-lhe um vigoroso papel ativo, além do mero fiscal de regras jurídicas. Esse papel ativo, embora necessário para proteger os direitos de primeira geração, era visto anteriormente com desconfiança, por ser considerado uma ameaça aos direitos do indivíduo. Contudo, sob a influência das doutrinas socialistas, constatou-se que a inserção formal de liberdade e igualdade em declarações de direitos não garantia a sua efetiva concretização, o que gerou movimentos sociais de reivindicação de um papel ativo do Estado para realizar o "direito de bem-estar social".

Nesse momento são reconhecidos os chamados direitos sociais, como direito a saúde, educação, previdência social, habitação, entre outros, que demandam prestações positivas do Estado para o seu atendimento e são denominados direitos de igualdade.

Os direitos de segunda geração são frutos das chamadas ações sociais na Europa e Américas, sendo seu marco à Constituição Mexicana de 1917 (que regulou o direito ao trabalho e a previdência social), a Constituição alemã de Weimar de 1919 (que, em sua parte II estabeleceu os deveres do Estado na proteção dos direitos sociais) e, no Direito Internacional, o Tratado de Versailles, que criou a Organização Internacional do Trabalho, reconhecendo direitos dos trabalhadores.

Os direitos de terceira geração, são aqueles de titularidade da comunidade, como o direito ao desenvolvimento, direito à paz, direito à autodeterminação e, em especial, o direito ao meio ambiente equilibrado. São chamados de direitos de solidariedade e são frutos da descoberta do homem vinculado ao planeta terra, com recursos finitos, divisão absolutamente desigual de riquezas em verdadeiros círculos viciosos de miséria e ameaças cada vez mais concretas à sobrevivência da espécie humana.

Bonavides (1997), escorado em lições de VASAK (1997), adicionou ainda o direito de comunicação e recentemente defendeu o nascimento da quarta geração ou dimensão, sendo resultante da globalização dos direitos humanos, correspondendo aos direitos de participação 
democrática, informação e direito ao pluralismo.

Piovesan (2017), ensina que uma geração não sucede a outra, mas com ela interage, estando em constante e dinâmica relação. Ademais, Cançado Trindade (1999), destaca que a metáfora da sucessão no tempo não é perfeita, havendo até descompasso em face do direito internacional, no qual alguns direitos sociais foram consagrados em convenções internacionais do trabalho.

\section{Política Nacional para às Pessoas em Situação de Rua: contextualizando}

Atualmente, vive-se um processo extremamente acelerado de urbanização da sociedade, que, impõe novas formas de lidar com o ambiente urbano e com suas implicações. A superação da invisibilidade social por falta de políticas públicas voltadas para o atendimento de demandas individuais e coletivas com a participação de pessoas em situação de rua precisa alcançar efetividade e concretização.

A promoção dos direitos civis, políticos, econômicos, sociais, culturais e ambientais alerta para que se busque sempre a implementação de políticas estruturantes. A responsabilidade do poder público pela elaboração e financiamento de políticas públicas torna-se urgente, e em 2005 com a Lei $n^{\circ} .11 .258$ do ano de 2005, que acrescentou o artigo 23 a Lei Orgânica de Assistência Social, promoveu a inclusão da população em situação de rua como público prioritário, e reconheceu as especificidades de quem vive nas ruas.

Com a articulação das políticas públicas federais, estaduais, municipais e do distrito federal, em 25 de outubro de 2006 através do Decreto sem número, o Presidente da República instituiu o Grupo de trabalho interministerial - GTI para elaborar a Política Nacional para a População em situação de rua. Esse foi um momento significativo por sua importância histórica pelo fato de trazer para o conjunto dos Ministérios esse tema até então desconhecido da maioria. O GTI foi formado por sete ministérios e teve representantes do Movimento Nacional da População de Rua e da Pastoral Nacional do Povo de Rua.

A integração das políticas públicas em cada nível de governo, entre outubro de 2007 e janeiro de 2008 foi realizado a contagem nacional da população em situação de rua em 71 municípios. Evidenciando-se a importância de conhecer a realidade vivida pela população em situação de rua pouco pesquisada até então.

A integração dos esforços do poder público e da sociedade civil para sua execução, 
através de consulta pública realizada em janeiro de 2009 foi possível um processo de participação ampliada das especificidades e demandas pertinentes à população em situação de rua de várias cidades do país.

A participação da sociedade civil, por meio de entidades, fóruns e organizações da população em situação de rua, para a elaboração, acompanhamento e monitoramento das políticas públicas, que ocorreu nos dias 19 e 20 de maio de 2009. Nesse momento foi realizado em Brasília o II Encontro Nacional Sobre População em Situação de Rua, e na ocasião, além de validar a política para às pessoas em situação de rua, foi apresentada a Carta Aberta ao presidente da República pelo Movimento Nacional da População de Rua.

Com isso, destaca-se o incentivo e apoio à organização da população em situação de rua e à sua participação nas diversas instâncias de formulação; controle social, monitoramento e avaliação das políticas públicas, respeito às singularidades de cada território e ao aproveitamento das potencialidades e recursos locais e regionais na elaboração, desenvolvimento, acompanhamento e monitoramento das políticas públicas; Implantação e ampliação das ações educativas destinadas à superação do preconceito, e de participação dos servidores públicos para melhoria da qualidade e respeito no atendimento deste grupo populacional; e democratização do acesso e fruição dos espaços e serviços públicos, são fatores basilares das diretrizes de ação em prol das pessoas em situação de rua.

A transformação de uma realidade se dá a partir do envolvimento de vários atores sociais. No entanto, o elemento principal é a participação das pessoas que vivenciam na pele a situação de moradores de rua. Tendo em vista as especificidades desse público e a dívida histórica com esses cidadãos, é preciso atentar para a superação de vulnerabilidade na qual se encontram (FIGUEIREDO, 2011).

\section{A CONSTITUIÇÃO BRASILEIRA E OS DIREITOS FUNDAMENTAIS: ANÁLISE SOB A ORDEM NACIONAL E INTERNACIONAL}

No tocante a Constituição da República Federativa do Brasil de 1988, que menciona os termos da "dignidade da pessoa humana" e "direitos humanos", no artigo $4^{\circ}$, inciso II, CF/88, o título II intitula-se direitos e garantias fundamentais, já o artigo $5^{\circ}$, LXXI adota o termo "direitos e liberdades constitucionais, o artigo 17, CRFB, destaca a expressão "direitos 
fundamentais da pessoa humana”. Quando trata das cláusulas pétreas, a Constituição ainda faz menção à expressão “direitos e garantias individuais" (artigo 60, parágrafo $4^{\circ}, \mathrm{CRFB}$ ).

Assim, para construir uma sociedade livre, solidaria e justa, garantir o desenvolvimento nacional, erradicar a pobreza e a marginalização, reduzir as desigualdades sociais e regionais e promover o bem de todos, sem preconceitos de origem, raça, sexo, cor, idade e quaisquer outras formas de discriminação, constituem os objetivos fundamentais do Estado brasileiro consagrados no artigo $3^{\circ}$, da Constituição de 1988.

Infere-se desse dispositivo a acentuada preocupação da Constituição Federal e 1988 em assegurar os valores da dignidade e do bem-estar da pessoa humana, como imperativo da justiça social. Na lição de Luño, 1984, p.288,

\begin{abstract}
Os valores constitucionais possuem uma tripla dimensão: a) fundamentadora, núcleo básico e informador de todo o sistema jurídico político; b) orientadora, metas ou fins distintos, ou que obstaculize a consecução daqueles fins enunciados pelo sistema axiológico constitucional; e c) critica, para servir de critério ou parâmetro de valoração para interpretação de atos ou condutas (...) os valores Constitucionais compõem, portanto, o contexto axiológico fundamentador ou básico para interpretação de todo o ordenamento jurídico; o postulado-guia para orientar a hermenêutica teleológica e evolutiva da Constituição; e o critério para medir a legitimidade das diversas manifestações do sistema de legalidade
\end{abstract}

Nesse sentido, o valor da dignidade da pessoa humana impõe-se como núcleo básico e informador de todo o ordenamento jurídico, como critério e parâmetro de valoração a orientar a interpretação e compreensão do sistema constitucional.

Com o desiderato de demonstrar a evolução histórica dos direitos humanos, evidenciando seus avanços e retrocessos, bem como velando dos ensinamentos lançados pelo autor Comparato (2013), pode-se apontar e sistematizar etapas históricas na afirmação dos direitos humanos:

a) A democracia ateniense e a república romana: basicamente a democracia ateniense consistiu na atribuição ao povo de eleger governantes e tomar diretamente em assembleia as decisões políticas mais importantes. Já a república romana, a limitação do poder político advinha de sistema de controle recíproco de diferentes órgãos políticos;

b) Idade Média: com a extinção do império romano do ocidente, iniciou-se uma nova civilização, formada pelo amálgama de instituições clássicas, de valores cristãos e 
costumes germânicos. E dessa reconstrução surgiram os feudos, os estamentos sociais (clero, nobreza e povo) e a concentração abusiva de poder na monarquia e na igreja). Foi justamente contra os abusos dessa reconcentração do poder que surgiram as primeiras manifestações de rebeldia: na península ibérica com a Declaração das Cortes de Leão de 1188 e, sobretudo, na Inglaterra com a Magna Carta de 1215;

c) O século XVII: durante os dois séculos que sucederam à idade média, a Europa conheceu um extraordinário recrudescimento da concentração de poderes, época em que desenvolveram as monarquias absolutistas. A crise da consciência europeia fez ressurgir na Inglaterra o sentimento de liberdade, alimentado pela memória da resistência a tirania. As devastações pela guerra civil reafirmaram o valor da harmonia social, reavivando-se os perigos representados pelo poder absoluto. No entanto, as liberdades pessoais garantidas pelo habeas corpus e pelo billofrights não beneficiavam indistintamente todos os indivíduos, mas somente, e preferencialmente, os dois primeiros estamentos (clero e nobreza). A atuação do Parlamento, por meio das ideias de governo representativo, foi a instituição responsável por limitar, ainda que em pouca medida, o poder monárquico;

d) A independência americana e a revolução francesa: tem-se como verdadeiro registro do nascimento dos direitos humanos na história. O artigo I da Declaração do Bom Povo de Virginia, em 16 de junho de 1776, nos Estados Unidos da América. Treze anos após a Revolução Francesa trazia as mesmas ideias de liberdade e igualdade dos seres humanos, reafirmando que "os homens nascem e permanecem livres e iguais em direitos" (art. $1^{\circ}$, da Declaração de Direitos do Homem e do Cidadão de 1789). As instituições da democracia liberal, com limitação vertical de poder (direitos individuais) e horizontais (separação das funções executivas, legislativa e judiciária), adaptam-se e moldam-se ao espírito de origem do movimento democrático;

e) O reconhecimento dos direitos humanos de caráter econômico e social: a perda da proteção familiar, religiosa e estatal tornou-se muito mais vulnerável às vicissitudes da vida e, especialmente, as mazelas advindas da concentração do capital e a pretensa igualdade de todos perante a lei. Essa isonomia formal rapidamente revelou-se como instrumento de opressão das empresar capitalistas 
em face da crescente legião de trabalhadores. Diante da brutal pauperização das massas proletárias, viu-se na Constituição mexicana de 1917 e da Constituição de Weimar de 1919 instrumentos de plena afirmação dos direitos econômicos e sociais, de sorte resgatar uma intervenção estatal para proteger e promover direitos das classes oprimidas;

f) A primeira fase da internacionalização dos direitos humanos: esta fase teve início na segunda metade do século XIX e findou-se com a $2^{\mathrm{a}}$ Guerra Mundial, manifestando-se basicamente em três setores: o direito humanitário (tem como marco a Convenção de Genebra de 1864, a partir da qual se fundou a Comissão Internacional da Cruz Vermelha), a luta contra a escravidão ( o Ato Geral da Conferencia de Bruxelas, de 1890), estabeleceu as primeiras regras para repressão ao tráfico de escravos) e a regulação dos direitos do trabalhador assalariado (marcado pela criação da Organização Internacional do Trabalho - OIT, em 1919);

g) A evolução dos direitos humanos a partir de 1945: ao cabo da Segunda Guerra Mundial, após incontáveis massacres e atrocidades de toda sorte, iniciados com o fortalecimento do totalitarismo estatal nos 30, a humanidade compreendeu, $\mathrm{m}$ ais do que em qualquer outra época da história, o valor supremo da dignidade humana. E no crepúsculo da humanidade, quando as violações de direitos faziam refletir sobre a essência da humanidade, parece ter surgido um pequeno feixe de luz que tentava incansavelmente resgatar a suprema dignidade inerente a cada ser humano. Esse movimento de resgate à dignidade humana foi personificado com a criação da Organização das Nações Unidas - ONU, regida pela Carta das Nações Unidas (1945), e especialmente pela Declaração Universal dos Direitos Humanos e pela Convenção Internacional sobre a prevenção e punição do crime de genocídio, ambas de 1948.

Assim, verifica-se que o reconhecimento e a proteção dos direitos humanos é fruto de longo processo histórico de evolução, um verdadeiro movimento pendular de avanços e retrocessos que constroem e reconstroem direitos humanos. Vale destacar como forma de catalogar tais direitos, alguns documentos normativos internacionais que contribuíram (e contribuem) para a construção dos direitos humanos: 
a) Magna Carta (1225): considerada por muitos como primeiro documento de direitos humanos, que limitava os poderes do monarca da Inglaterra;

b) PetitionoRights (1628): aprovada pelo parlamento inglês, também visava limitar os poderes do rei;

c) Habeas Corpus Act (1679): definiu e ampliou as prerrogativas concedidas ao remédio do habeas corpus, tornando-o efetivo;

d) Bill of Right (1689): documento elaborado pelo Parlamento inglês que passou a viger após a Revolução Gloriosa (1688-1689), prevendo limitações ao poder do monarca e disciplinando a atuação do Parlamento;

e) Declaração de Direitos do bom Povo da Virginia (1776): reconheceu direitos adstritos à condição humana e demonstrou grande preocupação com o governo democrático e a soberania popular;

f) Declaração dos Direitos do Homem e do Cidadão (1789): influenciada diretamente pela Revolução Francesa de 1789, tratava-se de declaração generalizante, isso é, concernente não só aos cidadãos, mas a toda a humanidade.

Analisando o ordenamento pátrio, nota-se que a Constituição da República Federativa do Brasil, 1988, consagrou em seu texto diversos direitos inerentes ao fato da pessoa humana, pelo simples fato dela existir, a qual inclusive é um dos fundamentos da República (art. $1^{\circ}$, III). Vê-se que a positivação dos direitos humanos na Constituição foi efetivada sob a terminologia de "direitos fundamentais". Por conseguinte, enquanto os Direitos Humanos estão previstos na ordem jurídica internacional, os Direitos Fundamentais estão positivados na ordem interna do Estado.

\section{CONCLUSÃO}

Não restam dúvidas de que a dignidade da pessoa humana, especificadamente das pessoas em situação de rua, é algo possível, porém, ainda, distante da nossa realidade, já que 
não se verifica maior dificuldade em identificar claramente situações em que os direitos dessas pessoas são "espezinhados" e "agredidos".

Porém, há que reconhecer que o conteúdo da noção de dignidade da pessoa humana, na sua condição de conceito jurídico-normativo, a exemplo de tantos outros conceitos vagos e abertos, reclama uma constante concretização e delimitação pela práxis constitucional, tarefa cometida a todos os entes estatais, daí o fortalecimento de políticas públicas para concretizar circunstâncias da dignidade da pessoa humana.

Não raro, as políticas públicas são utilizadas desvirtualmente como um abre-te-sésamo a permitir desmandos sobre a pessoa humana, por isso, destaca-se que o agente público não é dono dos bens e interesses públicos, exercendo apenas uma função administrativa delimitada pelo respectivo rol de suas competências funcionais. Não lhe é lícito dispor de bens, interesses ou agir segundo qualquer ordem de conveniência, paixões ou demandas diversas da anunciada pela juridicidade normativa constitucional.

Assim, o Estado, com a percepção de que o "problema" pessoas em situação de rua é um fenômeno social perene, estabelece políticas sociais para administrá-los, mas não cria mecanismos que visem minimizá-los, não obstante as graves e inaceitáveis violações pelas quais passam essas pessoas no seu dia a dia.

É necessário que se adote, paralelamente às medidas de amparo às pessoas em situação de rua, medidas preventivas para a reconstrução de vínculos sociais. Mister uma intensa articulação social, envolvendo governo e sociedade, com o intuito de enfrentamento desse grave problema social com reflexos no ambiente de segurança, mas de forma a dar uma solução e garantir uma vida digna às pessoas em situação de rua.

Para isso, tem-se que a corrente de igualdade de chances ou igualdade de oportunidades. É nesse contexto que se posicionam as normas relativas à educação e à saúde. Imagina-se que uma pessoa saudável e que tenha acesso à educação será capaz de construir sua própria dignidade em uma sociedade capitalista, que consagra a livre iniciativa, independentemente do auxílio da autoridade pública.

Nisso, destaca-se que para inclusão e garantia do mínimo existencial das pessoas em situação de rua torna-se preciso: 
a) Capacitação dos operadores de direitos do Estado (especialmente da força policial) quanto aos direitos humanos, principalmente aqueles concernentes à população em situação de rua, incluindo nos cursos de formação conteúdos sobre o tema;

b) Fortalecimento da Ouvidoria para receber denúncias de violação de direitos humanos em geral, e especialmente dos direitos das populações de rua;

c) Responsabilização e combate à impunidade dos crimes e atos de violência que tem essa população como público-alvo, ampliando, assim, a possibilidade de que a rua seja um espaço de maior segurança;

d) Oferta de assistência jurídica, educação, saúde, habitação e disponibilização de mecanismos de acesso a direitos, incluindo documentos básicos às pessoas em situação de rua, em parceria com órgãos de defesa de direitos.

Não é possível a construção de uma sociedade livre, justa e solidaria, com desenvolvimento nacional, se inexistente a identificação das pessoas em situação de rua, para posterior promoção dos direitos providos até mesmo do mínimo existencial assegurado pela condição de humanos.

Urge a adoção de uma política pública nacional, de caráter uniforme e obrigatório, vinculada aos princípios da universalidade e equidade, pelo Poder Legislativo, dirigida para o Estado e sociedade civil, de forma que a implementação dessas políticas públicas, atualmente desfragmentadas, não seja mera opção política ou do administrador público para sua execução.

\section{REFERÊNCIAS}

ABREU, Pedro Manoel. Processo e Democracia: O processo jurisdicional como locus da democracia participativa e da cidadania inclusiva no estado democrático de direito. São Paulo: editora conceitual, 2011.

ABREU, Edgar; SILVA, Lucas. Sistema financeiro nacional. S.l: método, 2017.

ADA, Pellegrini; ALMEIDA, Gregório Assagra de; GUSTIN, Miracy; LIMA, Paulo Cesar Vicente de; LEMACO, Rodrigo (Orgs). Direitos Fundamentais das Pessoas em Situação de Rua. 2 ed. Belo Horizonte: editora D'plácido, 2016. 
AGUIAR, M.M; IRIART, Jab. Significados e práticas de saúde e doença entre população de rua em Salvador, Bahia. 2012. Periódicos. Disponível em http://www.scielo.br/pdf/csp/v28n1/12.pdf. Acesso dem 12 de jul de 2018.

ALMEIDA, A. R. S. A emoção e o professor: um estudo a luz da teoria de Henri Wallon. Teoria e Pesquisa. V.13, n.2, mai/ago, 1997. Disponível em http:// www.fe.unicamp.br. Acesso em 12 de abril de 2017.

ALVES, Candice Lisboa (Org.). Vulnerabilidades e invisibilidades - Desafios contemporâneos para a concretização dos direitos humanos. Belo Horizonte: Arraes Editores, 2015.

ARAÚJO, José Henrique Mouta; CUNHA, Leonardo Carneiro da; RODRIGUES, Marco Antônio (Coord.). Fazenda Pública. $2^{\circ}$ ed. ver, ampl e atual. - Salvador: Juspovim, 2016.

ALSTON, Philip. Does the past matter? On the origins of human right. Na analysis of competing histories os the origins os International Human Rights Law. Havard Law Review, v. 126, p. 2075, 2013.

AMARAL, Diogo Freitas do. Curso de Direito Administrativo. Vol. II. 2. Ed. Coimbra: Almedina. 2012.

AVILA, Humberto. Teoria dos princípios. São Paulo: Malheiros. 2015.

AVRITZER, Leonardo. Impasses da democracia no Brasil. S.l: Civilização Brasileira, 2016.

BALESTERO, Gabriela Soares. Direito Constitucional e Processual democrático Estudos e Reflexões. S.1: Boreal, 2015.

BARCELLOS, Ana Paula de. Direitos Fundamentais e direito à justificativa do devido procedimento. Belo Horizonte: Fórum, 2017.

A eficácia jurídica dos princípios Constitucionais: $O$ princípio da Dignidade da pessoa Humana. Rio de Janeiro: Renovar, 2002.

BARCELOS, Renato de Abreu. Linguagem, discurso e deliberação: a democratização da discricionariedade no paradigma do Estado democrático de direito. Dissertação (Mestrado) - Programa de Pós-graduação em Direito. Pontifícia Universidade Católica de Minas Gerais. Belo Horizonte, 2014.

BARROSO, Luís Roberto. Temas de Direito Constitucional. s.l: Renovar, 2005.

BINENBOJM, Gustavo. Uma teoria do direito administrativo: direitos fundamentais, democracia e constitucionalização. $3^{\text {a }}$ ed., Rio de Janeiro: Editora Renovar, 2014.

BURSZYTIN, Marcel. Da pobreza à miséria, da miséria à exclusão: o caso das populações de rua. In: BURSZYTIN, Marcel (org) no meio da rua: nômades, excluídos e viradores. Rio de Janeiro: Garamond, 2003. 
BRASIL. Decreto n. 7053 de 23 de dezembro de 2009. Institui a Política Nacional para população em situação de rua e seu comitê Intersetorial de Acompanhamento e Monitoramento, e dá outras providências. Disponível em: www.presidencia,,gov.br. Acesso em julho de 2012a.

BRASIL. Decreto-Lei $n^{\circ}$ 37, de 02 de dezembro de 1937. Dispõe sobre partidos políticos. Disponível http//câmara.leg.br. Acesso em 12 de mai. de 2017.

BRASIL. Decreto n. 591, de 6 de julho de 1992. Dispõe sobre o pacto Internacional de Direitos Econômicos, Sociais e Culturais. Disponível: http://www.planalto.gov.br/ccivil/decreto. Acesso em 20 de mai de 2018.

BRASIL. Constituição da República Federativa do Brasil - A decisão proferida no Acordão 509 de 2002 (versando sobre o rendimento social de inserção), bem como os comentários tecidos por VIEIRA DE ANDRADE, José Carlos. Os direitos fundamentais da constituição portuguesa de 1976. 3. ed. Coimbra: Almeida, 2004.

BRASIL. Lei $\mathrm{n}^{\mathrm{o}}$ 7.347, de 24 de julho de 1985. Disponível em http://www.planalto.gov.br. Acesso em 15 de nov de 2018.

BRASIL. STJ, ROMS 11183/PR, Rel. Min José Delgado, DJ 4.9.00. Disponível http://www.stj.jus.br. Acesso em 18 de jan.2018.

BRASIL. Decreto n. 1.973, de $1^{\circ}$ de agosto de 1996. Dispõe sobre a Convenção interamericana para prevenir, punir e erradicar a violência contra a mulher. Disponível: http://www.planalto.gov.br/ccivil/decreto. Acesso em 20 de mai de 2018.

BRASIL. Decreto n. 19.841, de 22 de outubro de 1945. Dispõe sobre a Carta das Nações Unidas de 1945. Disponível: http://www.planalto.gov.br/ccivil/decreto. Acesso em 20 de mai. de 2018.

BRASIL. Decreto n. 2.754, de 27 de agosto de 1998. Dispõe sobre o Protocolo Adicional à Convenção Americana sobre Direitos Humanos Referente à abolição da pena de morte, de 1990. Disponível: http://www.planalto.gov.br/ccivil/decreto. Acesso em 3 de abr de 2018.

BRASIL. Decreto n. 3.321, de 30 de dezembro de 1999. Dispõe sobre o protocolo São Salvador, 1998. Disponível: http://www.planalto.gov.br/ccivil/decreto. Acesso em 20 de mai. de 2018.

BRASIL. Decreto n. 3.956, de 08 de outubro de 2001. Dispõe sobre a Convenção Interamericana sobre o Desaparecimento Forçado de pessoas, de 1994. Disponível: http://www.planalto.gov.br/ccivil/decreto. Acesso em 20 de mai de 2018.

BRASIL. Decreto n. 678, de 06 de novembro de 1992. Dispõe sobre o pacto de São Jose da Costa Rica, aprovado em 1969. Disponível: http://www.planalto.gov.br/ccivil/decreto. Acesso em 18 de nov de 2018. 
BRASIL. Decreto n. 7030, de 14 de dezembro de 2009. Dispõe sobre a Convenção de Viena sobre Direitos dos Tratados concluída em 1969. Disponível: http://www.planalto.gov.br/ccivil/decreto. Acesso em 20 de mai de 2018.

BRASIL. Decreto n. 98.386, de 09 de dezembro de 1989. Dispõe sobre a Convenção Interamericana para prevenir e punir a tortura, de 1985. Disponível: http://www.planalto.gov.br/ccivil/decreto. Acesso em 20 de mai de 2018.

BARROSO, Luiz Roberto; BARCELLOS, Ana Paula de. O começo da história. A nova interpretação constitucional e o papel dos princípios no direito brasileiro. In: BARROSO, Luís Roberto. Temas de Direito Constitucional. Rio de Janeiro: Renovar, 2005.

CANÇADO TRINDADE, Antônio Augusto. Tratado de direito internacional dos direitos humanos. Porto Alegre: Fabris, 1997.

CANÇADO TRINDADE, Antônio Augusto. "A questão da implementação dos Direitos Econômicos, Sociais e Culturais: Evolução e Tendências Atuais". Revista brasileira de estudos políticos, 1999.

COMPARATO, Fábio Konder. A afirmação histórica dos direitos humanos. 8 ed. São Paulo: Saraiva, 2013, p.50.

FIGUEIREDO, Gladston A; BOVE, Cristina; OLIVEIRA, Roseni T.S.F; LOPES, Claudenice R. Belo Horizonte em diálogo com a população em situação de rua: uma tarefa histórica. Revista Pensar BH. N. 29. Jul, 2011.

LUNO, Antonio Enrique Perez. Derechos Humanos, Estado de Derecho y Constitucion. Tecnos editorial, 1984

MORAES, Maria Celina Bodin. Na medida da pessoa humana. Estudos de Direito CivilConstitucional. Rio de Janeiro: Renovar, 2010.

PIOVESAN, Flávia. Proteção dos direitos sociais: desafios do ius commune sulamericano. Revista de estudos Constitucionais, Hermenêutica e teoria do Direito- RECHTD. V.3, n.2/dez.2012. Disponível http://revistas.unisinos.br/index.php/RECHTD. Acesso em 23 de out. de 2017

RIBEIRO, Carlos Antônio Costa; SCALON, Maria Celi. Mobilidade de classe no Brasil em perspectiva comparada. V.44, n.1. Rio de Janeiro, 2001. Disponível http://www.dx.doi.org/10.1590/50011. Acesso em 13 de mai. de 2017.

VASAK, Karel. A 30-year struggle. The sustained efforts to give for of law to the Universal Declaration of human Rights. The Unesco Courier, Paris, 1997. 